\title{
Control de nemátodos en maracuyá usando benzimidazoles en ácidos húmicos
}

\author{
Carlos A. Soria \\ Laboratorios Labitech Cia. Ltda., Quito. Pontificia Universidad Católica del Ecuador, Quito. \\ casoria@puce.edu.ec
}

Recibido: 2010-04-19, aprobado 2010-08-25

\begin{abstract}
RESUMEN.- Los nemátodos son un problema fitosanitario en los cultivos de maracuyá. Su presencia se asocia, generalmente, con el aparecimiento de nódulos radiculares que obstruyen el flujo savial, disminuyen la vida de la planta y afectan considerablemente su producción. Del estudio fitonemático del maracuyá, se descubre su susceptibilidad al ataque de géneros polifitófagos encontrados, como Meloidogyne, Helicotylenchus y Rotylenchus.

Los benzimidazoles son compuestos orgánicos cíclicos nitrogenados con actividad antiparasitaria. Bioterr de Labitech, un nematicida formulado con derivados de benzimidazol, nos permitió estudiar su efecto novedoso en el control de nemátodos, más aún, si se administra acompañado de ácidos húmicos (Orgánica, Labitech), conocidos como modificadores de los corpúsculos de suelo y como acarreadores moleculares, en presencia de saprófitos poco afectados por el benzimidazol. Los controles indicaron una infección significativa con nemátodos, algunos, formadores de nódulos radiculares, pocas raicillas nuevas, menor peso radicular y menor producción. Mientras que en los cultivos tratados, se observó lo contrario: disminución significativa de nemátodos, presencia de más raicillas, mayor peso radicular y aumento significativo de la producción.
\end{abstract}

PALABRAS CLAVE: maracuyá, nemátodos, control, benzimidazol, rendimiento.

ABSTRACT.- Nematodes are a very common phytosanitary problem for passion fruit, causing the appearance and proliferation of typical root nodules which obstruct sap flux, reduce yield production and plant's life expectancy. Susceptibility of this crop is mainly to the attack of phytonematodes belonging to the genera: Meloidogyne, Helicotylenchus and Rotylenchus.

Benzimidazoles are cyclic nitrogenated organic compounds with anti- parasite activity. Bioterr from Labitech, formulated with types of benzimidazole, allowed us to study its novel effect in phytonematode's control when administered with 
humic acids, known as soil corpuscle modifiers and molecular carriers. Little effect was found in saprofites also considered as soil modifiers. Controls indicated a significant nematode infection, evidenced by the presence of root nodules, absence of secondary roots, lower root weights and scarce production, contrary to the results observed after treatment, evidenced by a significant reduction of numbers of nematodes, presence of secondary roots, increased total root weight and better yields.

KEYWORDS: passion fruit, nematodes, benzimidazole, control, better yields.

\section{INTRODUCCION}

Los nemátodos fitófagos, phylum Nematoda, clase Secernentea del orden Tylenchida, son las plagas que más daño causan a la agricultura (1) ocasionando problemas como pudrición o daños a la raíz de más de 2000 especies de hortalizas, leguminosas y frutales $(2,3)$.

Cuando el parásito daña los tejidos externos de la raíz o avanza hacia el conducto interno radicular, inyecta sus toxinas esofágicas y puede transmitir virus, bacterias $u$ hongos que ingresan a través de las heridas ocasionadas. Se reporta, por ejemplo, infecciones con Fusarium oxysporum a través de lesiones causadas por Pratylenchus sp. (4) o Meloidogyne sp. (5).

El ataque del género Meloidogyne es el más común (5) y se caracteriza por el aparecimiento de nódulos o agallas en la raíz que obstaculizan el flujo de nutrientes y pueden causar necrosis tisular.

Pero los nematoparásitos son diversos, algunos de vida libre o ectoparásitos (Trychodoridos) fáciles de controlar; otros facultativos (ecto o endopará- sitos), productores de huevos con matrices gelatinosas (Meloidogyne, Tylenchus, Rotylenchus) o quistes (Globodera, Heterodera) difíciles de eliminar; y, además, otros endoparásitos exigentes (Pratylenchus, Rodopholus), cuyo control resulta aun más difícil por estar protegidos dentro de tejidos radiculares, por ende, difíciles de ser alcanzados y fácilmente transmisibles de una plantación a la siguiente (1).

Estos diferentes tipos de parasitismo, solos o en sinergismo entre ellos, debilitan a las plantas huéspedes, ocasionando pérdidas económicas calculadas en miles de millones de dólares a nivel mundial, ya sea por mermas en la producción, aumento de la mortalidad del cultivo o por la suma de las dos (2, 5,6 ).

Productos fosforados o carbamatados, tóxicos tanto para el usuario como para el medio ambiente, se han utilizado por mucho tiempo en controles fitosanitarios. En humanos y animales, el efecto de los organofosforados se mide por la inhibición de la colinesterasa, 
enzima que interviene en la hidrólisis de la acetocolina, en las sinapsis neuronales colinérgicas. El uso continuo de estos organofosforados se asocia con daños neuronales $(2,7,8)$.

El benzimidazol y la úrea sustituida son los componentes principales del Bioterr de Labitech Cia. Ltda., una nueva alternativa para control fitonemático, libremente soluble en el agua de riego y de fácil migración en el suelo, por difusión y convección.

En el Ecuador, el cultivo de maracuyá, Passiflora edulis, se ha extendido a aproximadamente 30000 ha, principalmente en las provincias de Los Ríos, Guayas, Manabí, Bolívar, Esmeraldas y Santo Domingo de los Tsáchilas (9). Los nemátodos están entre los problemas fitosanitarios más comunes de este cultivo.

Durante este estudio, se probaría la eficacia antinemática de una formulación con derivados de benzimidazol y ácidos húmicos, en maracuyá. Se reconocería y cuantificaría los diferentes tipos de nemátodos en muestras de suelo control y tratado. Se estudiaría los daños ocasionados a la raíz y se asociaría este parasitismo con disminución en los niveles de producción.

\section{MATERIALES Y METODOS}

\section{Cultivos}

Se utilizaron 6 ha de cultivos comerciales de maracuyá en cinco fincas pequeñas de Chone. Cada ha en producción constaba de 750 plantas adultas de dos años de edad. Tres de las fincas, totalizando 4 ha, fueron asignadas para recibir tratamiento; las otras dos no recibieron ninguno y sirvieron de control.

\section{Tratamiento}

Bioterr (Labitech Cia. Ltda.) es un nematicida consistente de $150 \mathrm{~g}$ de derivados de benzimidazol y $820 \mathrm{~g}$ de úrea amoniacal más excipiente, por kg. Orgánica (Labitech) es un desestresante $\mathrm{y}$ activador de suelos que contiene $150 \mathrm{~g}$ de ácidos húmicos por litro de producto.

Las plantas tratadas recibieron 188 mg de Bioterr (benzimidazol) y $188 \mathrm{mg}$ de Orgánica (ácidos húmicos), aplicados en $250 \mathrm{cc}$ de agua de riego por planta. El producto fue aplicado una sola vez, en drench, de acuerdo con las instrucciones del fabricante. Previo a la aplicación, el suelo debe estar húmedo a capacidad de campo, para favorecer la penetración del producto hacia el sector de las raíces secundarias donde se localiza mayormente la infección (10). El resultado que se obtenga, dependerá totalmente de esta condición.

\section{Conteo e identificación de nemátodos}

Muestras de $100 \mathrm{~g}$ de suelo colectadas al azar, totalizando aproximadamente $1 \mathrm{~kg}$ por cada finca, por control o por suelo tratado, fueron mezcladas en una funda plástica, separado los controles de los suelos tratados. 
De cada total de muestra proveniente de cada finca, se pesaron $20 \mathrm{~g}$ de suelo, cantidad que fue suspendida con agitación continua durante dos min, en $250 \mathrm{cc}$ de agua de la llave reposada (durante la noche) en botellas cilíndricas de boca ancha, de 500 cc de capacidad. Luego se dejó decantar durante 1 minuto y el sobrenadante fue filtrado por malla de tela fina.

A continuación se pasó por una malla de 40 um, y lo que quedó en la malla fue recolectado y lavado con 20 cc de agua en un vaso de precipitación. De esta fracción, se tomó una muestra volumétrica de $5 \mathrm{cc}$, la cual fue depositada en una caja petri para el conteo o identificación de nemátodos en 25 campos, usando un estéreo microscopio con 50 aumentos.

Se reportó el total observado por género, incluyendo estadíos larvales y adultos por volumen de muestra. El resultado obtenido en cada muestra se multiplicó por 20 y se reportó como número total por género (o grupo de saprófitos y otros) por $100 \mathrm{~g}$ de suelo. Los conteos corresponden al promedio de 3 repeticiones.

\section{Nódulos en las raíces}

Se estudiaron los nódulos radiculares en las raíces colectadas a $20 \mathrm{~cm}$ de profundidad, de cada una de las 20 plantas que sirvieron de control y por separado, de otras 20 que recibieron tratamiento.
Las raíces de cada grupo (15 g por planta) fueron mezcladas manualmente en fundas separadas, luego se pesaron $100 \mathrm{~g}$ de cada grupo y se contaron nódulos de $3 \mathrm{~mm}$ o más de diámetro. Los muestreos y conteos de los controles y de las plantas tratadas se hicieron a los 30 días posteriores a la aplicación del tratamiento; los nódulos encontrados se reportaron por $100 \mathrm{~g}$ de raíces en cada grupo y para cada uno de tres ensayos o repeticiones.

\section{Desarrollo radicular}

Se seleccionaron al azar y en forma separada tres plantas adultas tanto del cultivo control como del que recibió tratamiento. Se sacrificó cada una de estas plantas, se extrajo completamente la raíz y se procedió a pesarla y a reportarla en gramos, tanto el peso de las raicillas como el de la raíz total, incluido su peso promedio.

\section{Producción}

Durante tres semanas se registró la producción semanal de maracuyá tanto en los cultivos que recibieron tratamiento como en los que no recibieron, y el resultado se reportó como $\mathrm{kg}$ de producción semanal por ha; se calculó también la producción promedio semanal. Los datos extrapolados de la producción en $\mathrm{kg}$ por ha fueron obtenidos contabilizando el peso de la producción semanal de las dos fincas control, comparado con la producción de las tres fincas que recibieron tratamiento. 


\section{Estadística}

Se realizaron análisis de varianza para detectar diferencias estadísticas en las muestras ensayadas y adicionalmente pruebas de significación de Tukey al 0,05 .

\section{RESULTADOS}

Los resultados obtenidos (Figura 1, cultivo tratado) se expresaron como número de nemátodos por género $\mathrm{y}$ por muestra en $100 \mathrm{~g}$ de suelo, tanto para los controles como para las muestras tratadas. Muestreos y conteos se realizaron 30 días después de aplicado el nematicida con los ácidos húmicos.

Del conteo realizado en los suelos controles (Tabla 1), se pudo observar una infección considerable de nemátodos parásitos (entre 160 hasta 400 individuos por $100 \mathrm{~g}$ de suelo), de los géne-

ros Meloidogyne, Pratylenchus y Helicotylenchus, así como una población numerosa de saprófitos (entre $300 \mathrm{y}$ 360). También se detectaron números menores de Radophylus y Rotylenchus (entre 40 y 80) y de otros nemátodos (entre 100 y 160) que no pudieron ser identificados.

En las muestras de suelos que recibieron tratamiento, se notó una disminución significativa $(\mathrm{p}<0,05)$ en el número de nemátodos de casi todos los géneros parásitos con la excepción de Radophylus $(\mathrm{p}=0,058)$. Con el tratamiento, también se encontró una aparente disminución de saprófitos (de un promedio de 330 a 293), pero esta diferencia en los resultados no fue significativa $(p>0,05)$.

Se reportaron nódulos en las raíces tanto de los controles como de las plantas tratadas (Tabla 2). Se contaron de 125 a 155 nódulos

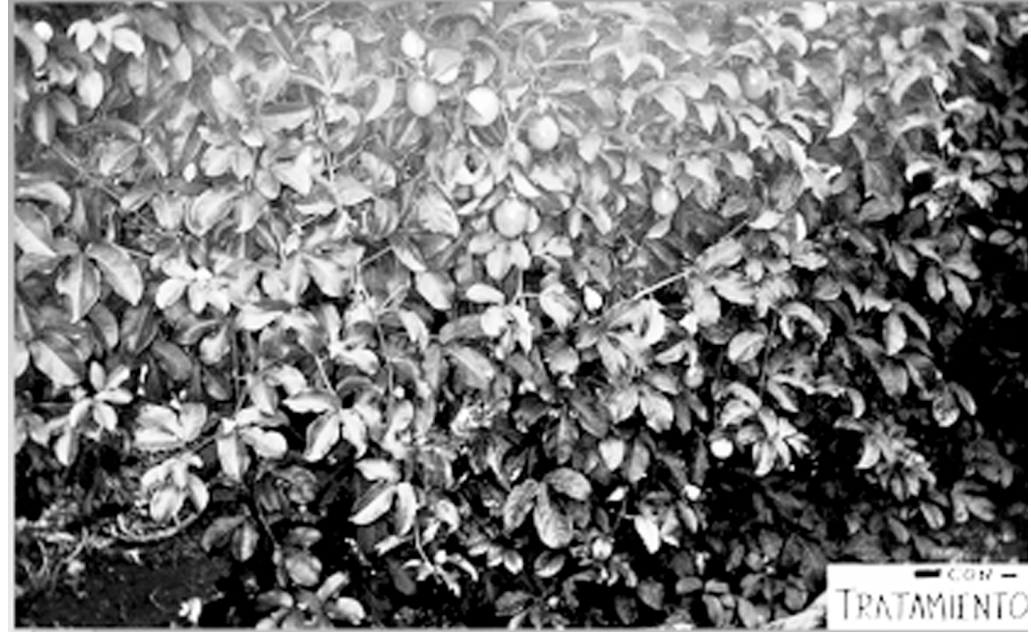

Figura 1. Cultivo de maracuyá tratado con benzimidazoles y ácidos húmicos (Foto de Abdón Tapia) $($ Prom $=138)$ por $100 \mathrm{~g}$ de raíces controles. Y en las plantas tratadas, el número fue de 120 a 150 (Prom = 133); por lo tanto, tampoco hubo diferencias significativas $(p>0,05)$ entre el número de nódulos en las raíces controles y los encontrados en las plantas tratadas. 
Tabla 1. Efecto del tratamiento con derivados de benzimidazoles y ácidos húmicos (a) sobre el número de nemátodos en $100 \mathrm{~g}$ de suelo cultivado con maracuyá.

\begin{tabular}{l|rrr|rrrr}
\hline \multirow{2}{*}{ Género/ grupo } & \multicolumn{3}{|c|}{ Controles } & \multicolumn{4}{c}{ Tratados } \\
\cline { 2 - 8 } & 1(b) & 2(b) & Prom(c) & 1(b) & 2(b) & 3(b) & Prom(c) \\
\hline Meloidogyne & 400 & 360 & 380 & 80 & 100 & 60 & 80 \\
Pratylenchus & 320 & 300 & 310 & 60 & 20 & 40 & 40 \\
Helicotylenchus & 160 & 180 & 170 & 40 & 20 & 20 & 27 \\
Rodophylus & 80 & 60 & 70 & 20 & 40 & 0 & 20 \\
Rotylenchus & 40 & 60 & 50 & 20 & 0 & 0 & 7 \\
Otros & 160 & 100 & 130 & 20 & 40 & 40 & 33 \\
Saprófitos & 300 & 360 & 330 & 280 & 340 & 260 & 293 \\
\hline
\end{tabular}

(a)Tratamiento: $188 \mathrm{mg}$ de Bioterr $+188 \mathrm{mg}$ de Orgánica en $250 \mathrm{cc}$ de agua /planta;

(b)Repeticiones: 1,2,3; (c)Prom: promedio

Tres plantas adultas del grupo control y 3 tratadas fueron sacrificadas para poder observar completamente sus raíces (Figura 2, Tabla 3). Se encontró diferencias significativas $(p<0,05)$ en el peso promedio de raicillas nuevas en las plantas tratadas (Prom $=8 \mathrm{~g}$ por planta), comparado con el de los controles (Prom $=3 \mathrm{~g}$ por planta). De igual forma, el peso total de las raíces sin tra- tamiento varió entre 197 y 210 g (Prom $=203 \mathrm{~g}$ ) en comparación con las plantas tratadas que mostraron pesos entre 250 y $281 \mathrm{~g}($ Prom $=262 \mathrm{~g})$, un resultado significativamente más alto que el reportado para los controles $(\mathrm{p}<0,05)$.

La producción semanal de las dos fincas $\sin$ tratamiento fue comparada con la de las otras tres fincas que sí fueron tratadas. Cada una de estas produc-

Tabla 2. Efecto del tratamiento con derivados de benzimidazoles y ácidos húmicos (a) sobre el número de nódulos en $100 \mathrm{~g}$ de raíces de maracuyá.

\begin{tabular}{ccc}
\hline \multirow{2}{*}{ Eúmero } & Número nódulos $/ \mathbf{1 0 0}$ g de raíces \\
\cline { 2 - 3 } & Controles & Tratados \\
\hline 1 & 155 & 130 \\
2 & 125 & 150 \\
3 & 134 & 120 \\
\hline
\end{tabular}

(a)Tratamiento: $188 \mathrm{mg}$ de Bioterr + $188 \mathrm{mg}$ de Orgánica en $250 \mathrm{cc}$ de agua /planta. 
ciones semanales (tres semanas) fue extrapolada y reportada como producción semanal de maracuyá por ha $(750$ plantas adultas por ha) en kg ( Tabla 4). Se encontró una producción promedio de $245 \mathrm{~kg}$ semanal por ha comparada con una producción significativamente mayor $(\mathrm{p}<0,05)$, promedio de $287 \mathrm{~kg}$ en las fincas tratadas.

\section{DISCUSION}

Los benzimidazoles son compuestos orgánicos cíclicos nitrogenados, derivados de los imidazoles, con intensa actividad antiparasitaria en animales y en el hombre. El tratamiento aplicado con benzimidazoles y ácidos húmicos, para uso agrícola, nos permitió estudiar su efecto novedoso en el control de los nemátodos del suelo (11).

La capacidad del tratamiento para disolverse totalmente en el agua de

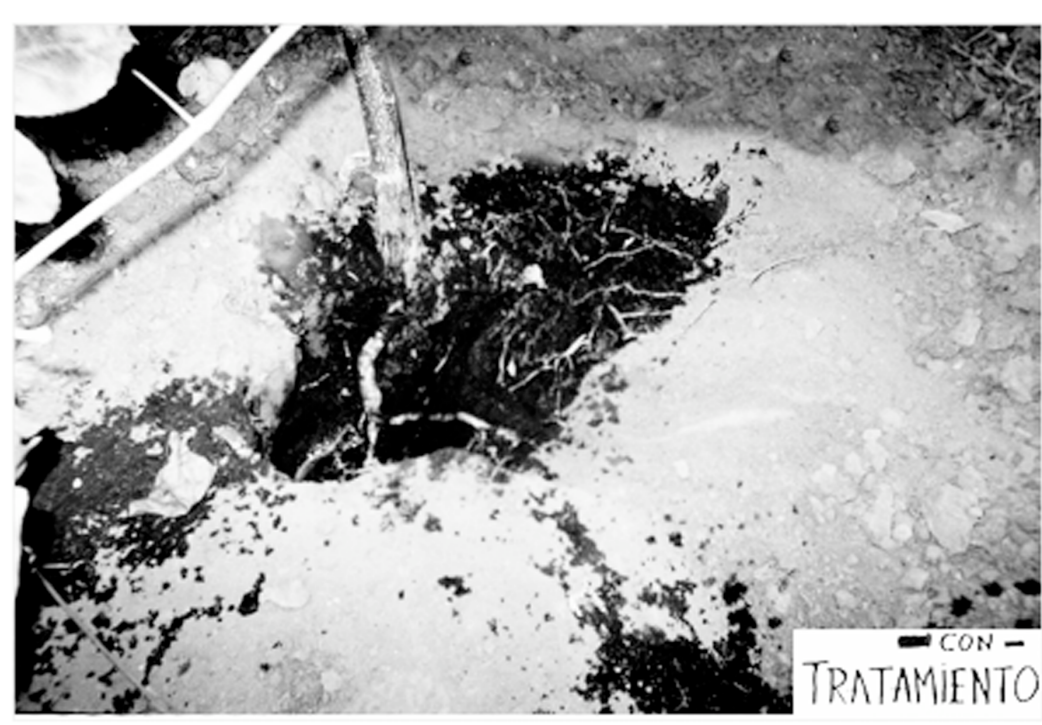

Figura 2. Raíces de maracuyá (Foto de Abdón Tapia) riego, facilita su uso. A esto se suma el hecho de ser aparentemente un producto no tóxico, de sello verde, cuyas moléculas activas, además de actuar por contacto, probablemente pueden ser absorbidas o acarreadas a través de la raíz hacia los tejidos infectados cercanos (12). Los otros componentes incorporados, por ejemplo, la úrea sustituida amoniacal y/o los ácidos húmicos, actuarían como moléculas catiónicas con poder surfactante $\mathrm{y}$ tensoactivo, que probablemente ayudarían en la penetración o acarreo del benzimidazol $\mathrm{y}$ de los nutrientes del suelo.

Se sabe que la absorción radicular de un pesticida en solución acuosa, dependerá de su formulación y entre otros, de la presencia de los ácidos húmicos $\mathrm{y}$ fúlvicos (13), como los administrados, cuya incorporación al suelo también ocasionan soltura corpuscular, oxigenación por aereación y solubilización por quelación de sales insolubles $\mathrm{u}$ otros principios activos no disueltos (datos no reportados).

De lo encontrado, se desprende que estos cultivos de maracuyá son bastante susceptibles al ataque de varios géneros de 
Tabla 3. Efecto del tratamiento (a) sobre el peso de las raicillas y raíces de plantas de maracuyá.

\begin{tabular}{ccccccccc}
\hline \multirow{2}{*}{$\begin{array}{c}\text { Peso } \\
\text { (g) }\end{array}$} & \multicolumn{3}{c}{ Sin tratamiento } & \multicolumn{5}{c}{ Tratados } \\
\cline { 2 - 9 } & $\mathbf{1 ( b )}$ & $\mathbf{2 ( b )}$ & $\mathbf{3 ( b )}$ & Prom(c) & $\mathbf{1 ( b )}$ & $\mathbf{2 ( b )}$ & $\mathbf{3 ( b )}$ & Prom(c) \\
\hline Raicillas & 3 & 4 & 2 & 3 & 8 & 10 & 7 & 8 \\
Raices & 203 & 197 & 210 & 203 & 255 & 250 & 281 & 262 \\
\hline
\end{tabular}

(a)Tratamiento: $188 \mathrm{mg}$ de Bioterr + $188 \mathrm{mg}$ de Orgánica en 250 cc de agua /planta;

(b)Planta número: 1,2,3; (c)Prom: promedio.

nemátodos polifitófagos (Tabla 1), de los cuales, los géneros Meloidogyne, Pratylenchus y Helicotylenchus fueron los más abundantes en el estudio de los grupos control. Otros, como Radophylus y Rotylenchus, se encontraron en números significativamente más bajos $(\mathrm{p}<0,05)$, comparados con Meloidogy$n e$, por ejemplo, pero no por eso pueden ser considerados infectivamente menos importantes, ya que algunos son endoparásitos portadores y transmisores de infecciones virales (14).

Fue claro el control de la infección después del tratamiento, evidenciado por la sanidad del cultivo (Figura 1) y la reducción significativa $(\mathrm{p}<0,05)$ en el número de los nemátodos encontrados (Tabla 1). El benzimidazol, mejor acarreado parcialmente por los ácidos húmicos, en contacto con el nemátodo, sea afuera en el suelo o dentro en la raíz, probablemente es absorbido a su sistema muscular, por contacto externo o con el alimento, provocando parálisis por inhibición enzimática e incapacidad para metabolizar la glucosa muscular. Interacciones del benzimidazol con las glicoproteínas o con los esteroles de las membranas parasitarias (15), podría

Tabla 4. Efecto del tratamiento con benzimidazoles y ácidos húmicos (a) sobre la producción extrapolada semanal de maracuyá en $\mathrm{kg} / \mathrm{ha} / 750$ plantas.

\begin{tabular}{lccccccc}
\hline \multicolumn{2}{c}{ Sin tratamiento } & \multicolumn{5}{c}{ Tratados } \\
\hline $\mathbf{1 ( b )}$ & $\mathbf{2 ( b )}$ & $\mathbf{3 ( b )}$ & Prom(c) & $\mathbf{1 ( b )}$ & $\mathbf{2 ( b )}$ & $\mathbf{3 ( b )}$ & Prom(c) \\
\hline 265 & 240 & 230 & 245 & 280 & 300 & 280 & 287 \\
\hline
\end{tabular}

(a)Tratamiento: $188 \mathrm{mg}$ de Bioterr $+188 \mathrm{mg}$ de Orgánica en $250 \mathrm{cc}$ de agua /planta.

(b)Semana número: 1,2,3.

(c)Prom: promedio. 
desencadenar en catástrofes metabólicas suficientes como para causar su mortalidad (16).

La poca mortalidad observada en los saprófitos después del tratamiento, también resulta interesante (Tabla 1). Esta selectividad podría explicarse porque éstos, al alimentarse de tejidos muertos, en vez de tejidos vivos, como es su hábito, no ingieren los antiparasitarios incorporados sistémicamente a la savia $(1,12)$.

La presencia de saprófitos es una ventaja para el cultivo porque al ser convertidores de tejidos muertos en substratos, algunos asimilables, se vuelven remodeladores y acondicionadores iónicos de los suelos, más aun, en presencia de ácidos húmicos (13). Es la actividad fisiológica de estos nemátodos, más la presencia de los ácidos húmicos que actúan como quelantes o acarreadores iónicos, lo que permite la liberación de nutrientes que pueden estar localizados en algunos nichos y no en otros (17), causando, además, un mejor aprovechamiento del agua y del oxígeno del suelo (8).

El ataque del género Meloidogyne es peculiar en más de 3.000 variedades de cultivos (18) y se caracteriza por estimular una multiplicación de células gigantes y aledañas, formadoras de nódulos, donde se acumulan toxinas, celulasas, proteinasas o radicales oxigenados de alta reactividad que suprimen procesos fotosintéticos y de respiración.
El cultivo queda disminuido en el flujo de nutrientes y agua por necrosis radicular y por el aparecimiento de infecciones bacterianas, fungosas $\mathrm{y}$ virales (5) que ocasionan bajos rendimientos, como se pudo observar en los cultivos control. Estos últimos mantuvieron poblaciones altas de nemátodos (Tabla 1) y baja producción (Tabla 4).

Al estudiar las raíces control y las del grupo tratado (Figura 2), se encontró en ambos la presencia de agallas (Tabla 2) en números similares; es decir, en cifras estadísticamente no significativas $(\mathrm{p}>0,05)$. Pero sí se observó una renovación significativamente abundante de raicillas (Tabla 3 ) en los grupos tratados $(p<0,05)$.

Estos resultados se explican porque una vez iniciado el daño del tejido con el aparecimiento de los nódulos (6), éstos permanecen temporalmente aun en ausencia de nemátodos que podrían haber sido ya controlados por el tratamiento (12).

El número bajo de nemátodos que se encontraron en el suelo tratado 30 días atrás, podría explicarse porque los benzimidazoles no sufren fácilmente biotransformaciones (19) por descarboxilización, debido a su estructura anillada que les confiere estabilidad; esta propiedad, permite que estas moléculas puedan permanecer activas en el suelo por más de 30 días, quizá al mantenerse débilmente queladas a los ácidos húmicos. Esta característica de los derivados ani- 
llados imidazólicos se traduce en la obtención de mejores cosechas (Tabla 4), debido, entre otros, al control fitonemático prolongado, a la disponibilidad de nutrientes acondicionados por los nemátodos saprófitos y por los ácidos húmicos, así como al mejoramiento de la absorción que pudiera explicarse por el aumento de la masa radicular, especialmente de las raicillas absorbentes (Tablas 1,2,3). Además del ahorro que ocasiona la implementación de tratamientos menos seguidos requeridos para romper ciclos nemáticos (5) que ocurren aproximadamente cada 30 días.

\section{LITERATURA CITADA}

1. Lamberti F., Greco N., Basile M., 1986. Treatments of soil-nematological aspects. Bulletin OEPP/EPPO Bulletin 16, 327-333.

2. Fleming C., McKinney S., McMaster S., Johnston M., Donnelly P., Kimber, M., Maule A., 2007. Getting to the root of neuronal signaling in plant-parasitic nematodes using RNA interference. Nematology 9 (3), 301-315.

3. Ubidia P., Soria C., 2006. Revisión de efectos y daños causados por los nemátodos fitoparásitos en cultivos importantes en la producción agrícola. XXX Jornadas Nacionales de Biología. Sociedad Ecuatoriana de Biología y Pontificia Universidad Católica del Ecuador. Libro de resúmenes, p. 112.
4. Castillo P., Jimenez R., Gomez A., Vovlas N., 1995. Parasitism of the root-lesion nematode Pratylenchus thornei on chickpea. Plant Pathology 44, 728-733.

5. Leonard D., 1991. The nematode. Horticulture 69 (3), 1-7.

6. Hofmann J., Grundler M., 2007. How do nematodes get their sweets? Solute supply to sedentary plant-parasitic nematodes. Nematology 9 (4), 451-458.

7. Pink R., Hudson A., Mourie's M., Bendig M., 2005. Opportunities and challenges in antiparasitic drug discovery. Nature reviews 4, 727-740.

8. Blouin M., Zuily-Fodil Y., PhamThi A., Laffray D., Reversat G., Pando A., Tondoh J., Lavelle P., 2005. Belowground organism activities affect plant aboveground phenotype, inducing plant tolerance to parasites. Ecology letters 8, 202208.

9. Servicio de Información Agropecuaria del Ministerio de Agricultura y Ganadería del Ecuador. Presentación de Maracuyá (Ing. Olmedo Luna). El cultivo de maracuyá en el Ecuador (Ing. Pablo Rizzo Pástor). http://www.sica.gov.ec/cadenas/2009.

10. Araya M., Vargas A., Cheves A., 1999. Nematode distribution in roots of banana (Musa AAA cv. Valery) in relation to plant height, distance from the pseudostem and 
soil depth. Nematology 1 (7-8), 711716.

11. Soria C., 2006. Benzimidazoles en el control de nemátodos. XXX Jornadas Nacionales de Biología. Sociedad Ecuatoriana de Biología y Pontificia Universidad Católica del Ecuador. Libro de resúmenes, p. 51-52.

12. Soria C., 2009. Bioterr Labitech, un nuevo fitonematicida a base de benzimidazol. Rev Ecuat Med Cienc Biologicas 30 (1,2), 28-41.

13. Kyriakopoulos G., Doulia D., 2006. Adsorption of pesticides on carbonaceous and polymeric materials from aqueous solutions: a review. Separation and Purification Reviews 35, 97-191.

14. González L. 1985. Introducción a la Fitopatología. 4ta Edición, Editoril IICA, San José de Costa Rica, Costa Rica, p. 57-64.

15. Vervelde L., Van Leeuwen M., Kruidenier M., Kooyman F., Huntley J., VaDie I., Cornelissen A., 2002. Protection studies with recombinant excretory / secretory proteins of
Haemonchus contortus. Parasite Immunology 24, 189-201.

16. Kerboeuf D., Riou M., 2006. Nematodes as Models for the Study of the Regulation of Activity of P-glycoproteins in Multidrug Resistance (MDR). Anti-Infective Agents in Medicinal Chemistry 5, 389-402.

17. Wurst S., Langel R., Scheu S., 2005. Do endogeic earthworms change Plant competition? A microcosm study. Plant and Soil 271, 123-130.

18. Castagnone P., 2002. Genetic variability in parthenogenetic root-knot nematodes, Meloidogyne spp., and their ability to overcome plant resistance genes. Nematology 4, 605-608.

19. Ballinger D., Kollmorgen J., 1986. Control of take-all of wheat in the field with benzimidazole and triazole fungicides applied at seeding. Plant Pathology 35, 67-73. 